\title{
Treasure or artifact: a decade of p63 research speaks for itself
}

\author{
Cell Death and Differentiation (2010) 17, 180-183; doi:10.1038/cdd.2009.157; published online 30 October 2009
}

\author{
Dear Editor,
}

The p63 gene encodes six transcription factors, which are generated by the use of two promoters, giving rise to TA and $\Delta \mathrm{N} \mathrm{N}$-termini, and alternative splicing, giving rise to three C-termini, termed $\alpha, \beta$, and $\gamma^{1}$ p63 is expressed primarily in stratified epithelia, including the epidermis, as well as in epithelial appendages. ${ }^{2}$ To investigate the role of p63 in these tissues, several p63 knockout mice have been generated. ${ }^{3-6}$ Of these, $\mathrm{p} 63^{\mathrm{Brdm} 2 / \mathrm{Brdm} 2}$ mice, generated by the Bradley laboratory, ${ }^{6}$ have been widely used by numerous research groups. These groups have consistently reported that p63 ${ }^{\mathrm{Brdm} 2 / \mathrm{Brdm} 2}$ mice fail to develop an epidermis, internal epithelia, and epithelial appendages. ${ }^{7-17}$ Wolff et al. ${ }^{18}$ have recently re-evaluated the $\mathrm{p} 63^{\mathrm{Brdm} 2 / \mathrm{Brdm} 2}$ mice and reported that early stages of epidermal and hair follicle morphogenesis occur in these mice. Further, Wolff et al. assert that one or more truncated p63 proteins are expressed from the $\mathrm{p} 63^{\mathrm{Brdm} 2}$ allele, leading them to conclude that these truncated p63 proteins are sufficient to initiate the early stages of epidermal morphogenesis.

The work by Wolff et al. contradicts a large body of literature by several independent research groups in which the developmental phenotype of $\mathrm{p} 63^{\mathrm{Brdm} 2 / \mathrm{Brdm} 2}$ mice has been extensively characterized. Most strikingly, it has been well-documented that the epidermis fails to develop in p63 ${ }^{\text {Brdm2/Brdm2 }}$ mice. ${ }^{6}$ This failure to develop an epidermis was found to result from an inability of the surface ectoderm, the single-layered epithelium that initially covers the developing embryo, to commit to an epidermal lineage. ${ }^{10}$ Thus, the surface epithelium of $\mathrm{p} 63^{\mathrm{Brdm} 2 / \mathrm{Brdm} 2}$ mice remains singlelayered throughout gestation. Consistent with these findings, the $\mathrm{p} 63^{\mathrm{Brdm} 2 / \mathrm{Brdm} 2}$ surface epithelium expresses keratins K8 and $\mathrm{K} 18$, structural proteins that are normally expressed in the surface ectoderm before the commitment to the epidermal lineage $^{10}$ (Figure 1). In contrast, the surface epithelium of p63 ${ }^{\mathrm{Brdm} 2 / \mathrm{Brdm} 2}$ mice does not express markers of epidermal development and differentiation, including K14 and Perp, at any developmental stage ${ }^{9,10}$ (Figure 1). As a result of the failure to develop an epidermis, $\mathrm{p} 63^{\mathrm{Brdm} 2 / \mathrm{Brdm} 2}$ mice do not develop an epidermal barrier and die shortly after birth owing to excessive water loss. ${ }^{6}$ In addition to the epidermis, structures of which the development relies on reciprocal signaling between the epithelium and the underlying mesenchyme, such as teeth and hair follicles, fail to develop in p63 ${ }^{\text {Brdm2/Brdm2 }}$ mice. $6,7,11$ Moreover, the finding that hair follicle and dental placodes do not form in $\mathrm{p} 63^{\mathrm{Brdm} 2 / B r d m 2}$ mice shows that appendage development does not initiate in p63 ${ }^{\text {Brdm2/Brdm2 }}$ mice. $^{7}$ Finally, internal epithelia, including the bladder, ${ }^{15}$ prostate, ${ }^{13}$ cervicovaginal epithelia, ${ }^{8,12}$ esophagus, ${ }^{14}$ and testis, ${ }^{17}$ also fail to develop normally in $\mathrm{p} 63^{\mathrm{Brdm} 2 / \mathrm{Brdm} 2}$ mice.

Using the same $\mathrm{p} 63^{\mathrm{Brdm} 2 / \mathrm{Brdm} 2}$ mice as in the abovedescribed literature, Wolff et al. describe strikingly different phenotypes. ${ }^{18}$ In sharp contrast to previous studies, Wolff et al. report that, except for limb morphogenesis, embryonic development proceeds essentially normally in $\mathrm{p} 63^{\mathrm{Brdm} 2 / \mathrm{Brdm} 2}$ mice until E15. At this developmental stage, the authors did not observe a marked difference between $\mathrm{p} 63^{\mathrm{Brdm} 2 / \mathrm{Brdm} 2}$ skin and wild-type skin. Instead, they observed that, like in control skin, p63 ${ }^{\mathrm{Brdm} 2 / \mathrm{Brdm} 2}$ epidermis was multilayered and that hair follicle buds were present. In addition, they found that p63 ${ }^{\text {Brdm2/Brdm2 }}$ epidermis expressed K14 and Perp, further suggesting that the epidermis is normal. Even though Wolff et al. report that $\mathrm{p} 63^{\mathrm{Brdm} 2 / \mathrm{Brdm} 2}$ skin is normal at $\mathrm{E} 15$, only patches of normal skin were observed in E18 p63 ${ }^{\text {Brdm2/Brdm2 }}$ embryos. Unfortunately, intermediate developmental stages were not evaluated, and thus the reason for the apparent disintegration of the skin remains unclear. The authors attribute the normal development of the epidermis, hair follicles, and internal epithelia until E15 to their finding that one, or perhaps two, truncated $\mathrm{p} 63$ proteins are expressed from the $p 63^{\mathrm{Brdm} 2}$ allele. The western blot analysis performed by Wolff et al. fails to convincingly demonstrate that such truncated proteins are actually expressed in $\mathrm{p} 63^{\mathrm{Brdm} 2 / \mathrm{Brdm} 2}$ mice. Further, we have performed extensive western blot analyses on embryonic p63 $3^{\mathrm{Brdm} 2 / \mathrm{Brdm} 2}$ skin samples and have never observed a band corresponding to a truncated p63 protein (Figure 2). ${ }^{7}$ However, even if truncated p63 proteins are expressed from the $p 63^{B r d m 2}$ allele, they would not correspond to endogenous p63 isoforms. Whereas the $\mathrm{N}$-termini of the presumed truncated proteins are identical to those of endogenously expressed p63 proteins, the $\mathrm{C}$-termini lack the unique exons for $\alpha, \beta$, or $\gamma$ isoforms. Although the authors argue that these truncated proteins functionally resemble TAp63 $\gamma$ and $\Delta \mathrm{Np} 63 \gamma$, this is not convincingly demonstrated. Thus, the conclusion that these truncated p63 proteins, if they exist, can faithfully regulate epidermal and hair follicle morphogenesis is not supported by the data.

To reconcile the differences in observed phenotypes reported by Wolff et al. and other groups, it is important to bear in mind that the $\mathrm{p} 63^{\mathrm{Brdm} 2}$ allele was generated by insertional mutagenesis, resulting in duplication of a segment of the p63 gene. ${ }^{6}$ Follow-up studies have consistently shown that $\mathrm{p} 63^{\mathrm{Brdm} 2 / \mathrm{Brdm} 2}$ mice do not express detectable levels of 
Wild-type

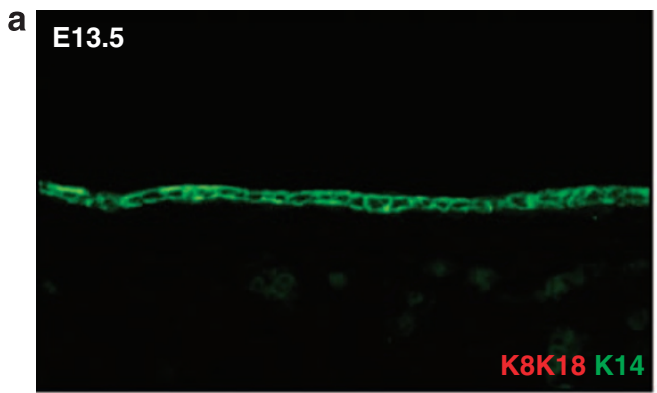

b E16.5

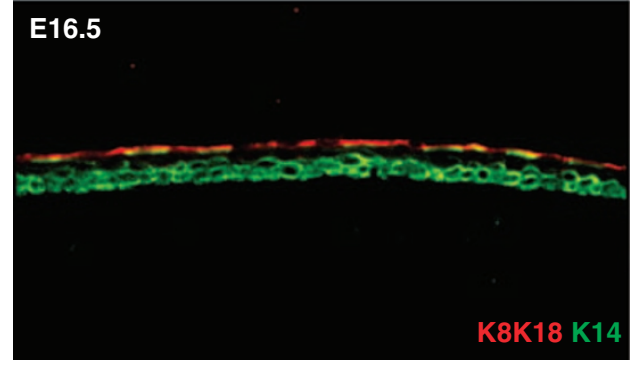

p63 ${ }^{\text {Brdm2/Brdm2 }}$
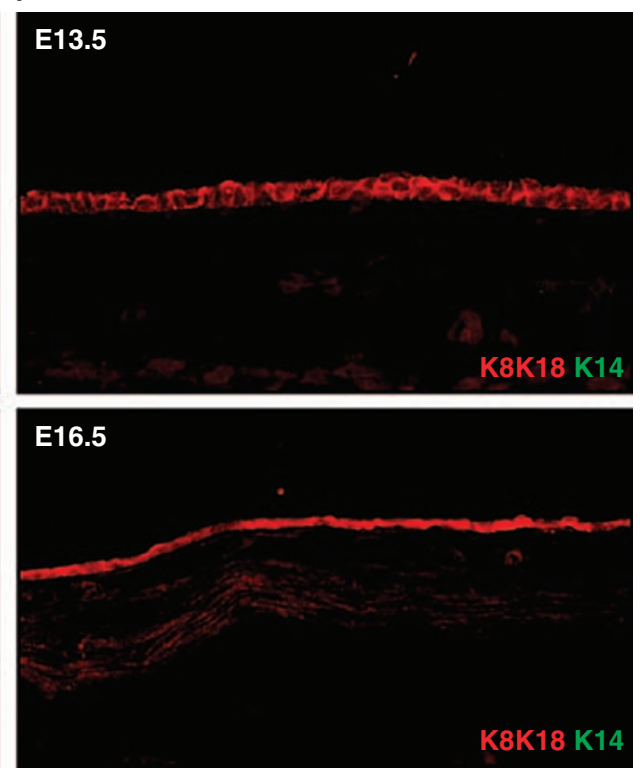

Figure 1 Skin phenotype of $\mathrm{p} 63^{\text {Brdm2/Brdm2 }}$ mice. Immunofluorescence analysis using antibodies against K14 (green), a marker for epidermal keratinocytes, and $\mathrm{K} 8 / \mathrm{K} 18$ (red), markers for single-layered epithelia. Both at E13.5 (a) and E16.5 (b), the p63 $3^{\mathrm{Brdm} 2 / \mathrm{Brdm} 2}$ epidermis expresses K8/K18, but not K14, indicating that the surface epithelium has not adopted an epidermal fate. In contrast, the epidermis from control littermates expresses K14, but not K8/K18. The K8/K18-expressing cells on the surface of the E16.5 control epidermis represent cells of the periderm, which is a transient layer of cells that may protect the underlying epidermis

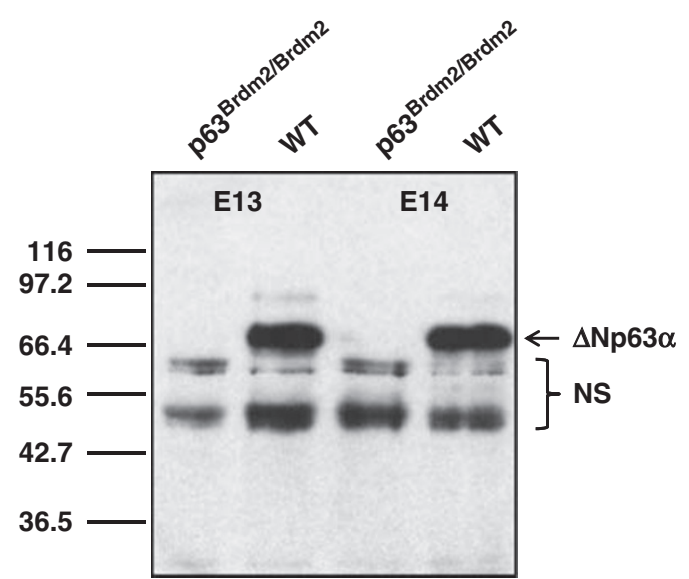

Figure 2 Embryonic p63 $3^{\text {Brdm2/Brdm2 }}$ skin does not express any p63y-like proteins. Western blot analyses on protein extracts isolated from the skin of E13 and E14 p63 Brdm2/Brdm2 and control littermates. Note the absence of a fastmigrating band corresponding to truncated $\mathrm{p} 63$ proteins in the $\mathrm{p} 63^{\mathrm{Brdm} 2 / \mathrm{Brdm} 2}$ samples. The molecular weight of the $\mathrm{p} 63 \gamma$-like protein described by Wolff et al. is between 36.5 and $42.7 \mathrm{kDa}$. NS, non-specific bands

p63 protein, thus demonstrating that the observed phenotypes are caused by a complete loss of p63 expression. $7,8,13,14$ However, because of the partial duplication of the p63 gene, reversion events in which the wild-type p63 allele is re-created through spontaneous homologous recombination occur sporadically in these mice (Figure 3). ${ }^{19}$ In fact, we routinely observe such reversion events in $163^{\mathrm{Brdm} 2 / \mathrm{Brdm} 2}$ embryos of all developmental stages. Although these patches are generally rare and small in size, on some occasions, they are larger and easily discernable by eye (Figure 4a). As expected, cells within these patches show normal epidermal differentiation, as demonstrated by histological analysis as well as by the analysis of expression of markers of epidermal differentiation (Figure 4b-d and data not shown).

Wolff et al. attempt to exclude the possibility that the normal-appearing skin they observe in $\mathrm{p} 63^{\mathrm{Brdm} 2 / \mathrm{Brdm} 2}$ mice is a result of spontaneous reversion events by analyzing p63 transcripts in $\mathrm{p} 63^{\mathrm{Brdm} 2 / \mathrm{Brdm} 2}$ embryos. Although they were unable to detect transcripts representing the $\alpha, \beta$, and $\gamma$ C-termini of p63, the analysis was performed on mRNA isolated from whole embryos, rather than on mRNA isolated from microdissected areas of normal-appearing skin. Therefore, any wild-type p63 transcripts, expressed from a reverted allele, would have been easy to miss in this analysis. In fact, this seems to be the most likely explanation for these observations, especially considering that reversion events are known to occur in $\mathrm{p} 63^{\mathrm{Brdm} 2 / \mathrm{Brdm} 2}$ mice (Figure 3 ). In addition to reversion events, other types of novel genetic changes could have occurred in the $\mathrm{p} 63^{\mathrm{Brdm} 2 / \mathrm{Brdm} 2}$ mice, which may account for the phenotypic differences that were observed by Wolff et al. (reviewed by Aberdam and Mantovani ${ }^{20}$ ).

In summary, the phenotypic analysis of $\mathrm{p} 63^{\mathrm{Brdm} 2 / \mathrm{Brdm} 2}$ mice presented by Wolff et al. ${ }^{18}$ is inconsistent with the extensive documentation of the $\mathrm{p} 63^{\mathrm{Brdm} 2 / \mathrm{Brdm} 2}$ phenotype by several independent research groups. ${ }^{7-17}$ Whether this is caused by an increase in reversion events in the $\mathrm{p} 63^{\mathrm{Brdm} 2 / \mathrm{Brdm} 2}$ mice used by Wolff et al. remains to be determined. However, as Wolff et al. report extended areas of the normal epidermis in the $\mathrm{p} 63^{\mathrm{Brdm} 2 / \mathrm{Brdm} 2}$ mice they used, it is most likely that the mice analyzed by Wolff et al. are genetically not identical to those generated by Mills et al. Thus, the suggestion by Wolff et al. that all previous work involving $\mathrm{p} 63^{\mathrm{Brdm} 2 / \mathrm{Brdm} 2}$ mice needs to be re-interpreted is not warranted. 
a $12-3-4,5-6-8,9-10-11-12-13-14-15$

b

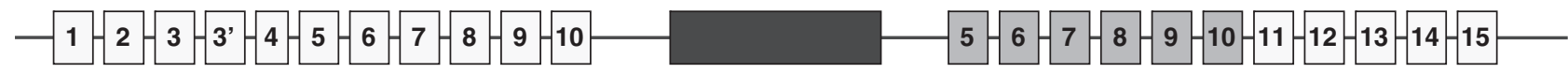

c

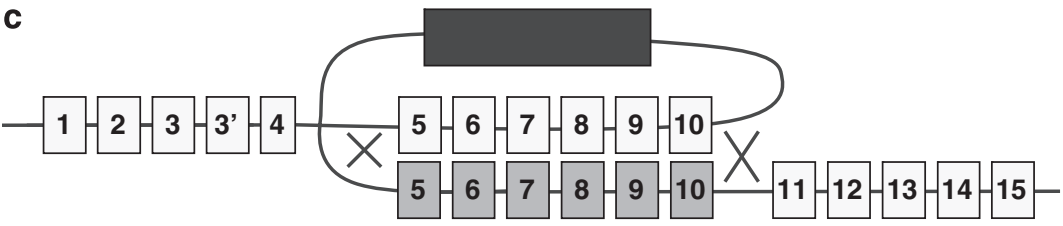

d $1-2-3-3^{\prime}-4-5-6-7-8-9-10-11-12-13-14-15$ $1,2-3-3,4-5-6-7,8-9-10-11-12-13-14-15$

Figure 3 Reversion of the $p 63^{\text {Brdm2 }}$ allele into a wild-type p63 allele. (a) Structure of the wild-type p63 allele. Light gray boxes indicate exons. (b) Structure of the p63 ${ }^{\mathrm{Brdm} 2}$ allele. The $\mathrm{p} 63^{\mathrm{Brdm} 2}$ allele was generated by insertional mutagenesis, resulting in a duplication of exons 5-10 (gray) and insertion of a selection cassette (dark gray). (c) Spontaneous homologous recombination at the p63 $3^{\text {Brdm2 }}$ locus can occur, resulting in (d) restoration of a wild-type p63 allele. The restored p63 allele can contain exons 5-10 from the original p63 allele (light gray), or exons 5-10 derived from the targeting vector (gray)
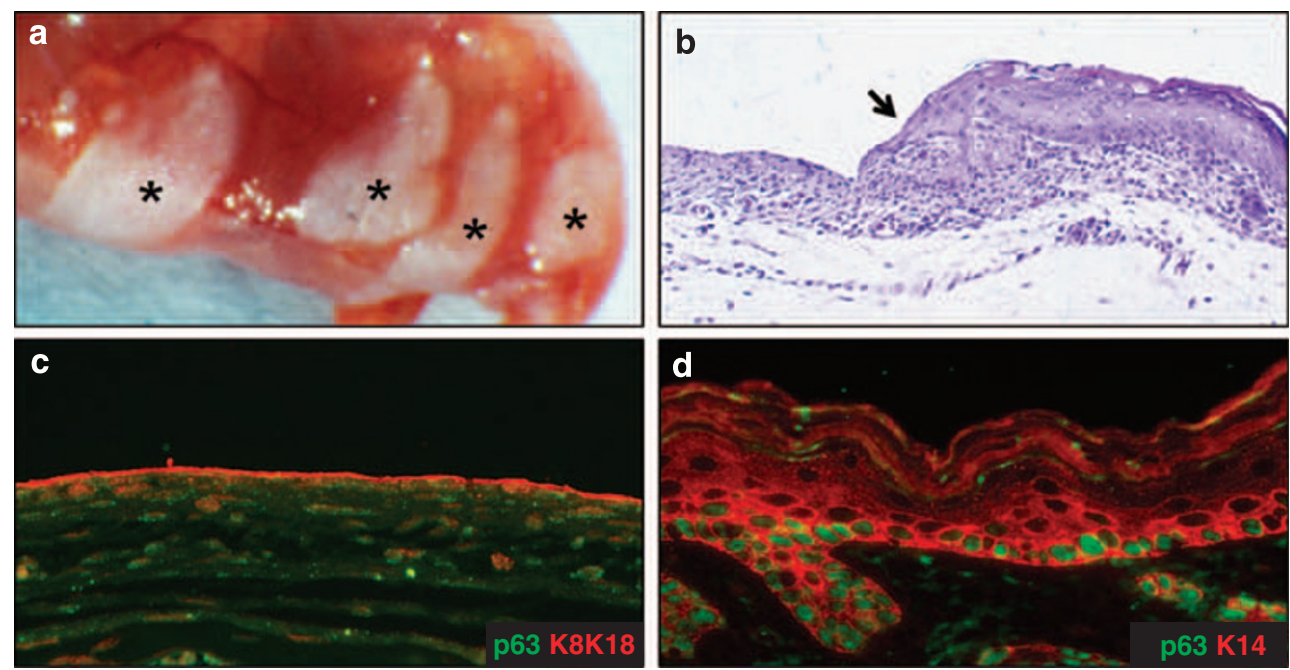

Figure 4 Reversion events in p63 $3^{\text {Brdm2/Brdm2 }}$ mice. (a) Patches of normal-looking skin on an E18.5 p63 ${ }^{\text {Brdm2/Brdm2 }}$ embryo. Asterisks indicate reversion events, where re-expression of p63 has resulted in normal epidermal development. (b) Histological analysis of a reversion event that occurred in an E18.5 p63 $3^{\text {Brdm2/Brdm2 }}$ embryo. The epidermis on the left side is single-layered, and represents epidermis where p63 is not expressed (c). The epidermis on the right side is stratified, and represents a reversion event where p63 is re-expressed (d). Arrow in (b) indicates transition between single-layered and stratified epidermis. The images in (c) and (d) were taken from sections of the same embryo stained with antibodies against p63 (green) and either K8K18 (c, red) or K14 (d, red). Images in (a) and (b) provided by Dr. Alea A Mills

\section{Conflict of interest}

The authors declare no conflict of interest.

\section{Mikkola ${ }^{1}$, A Costanzo $^{2}$, I Thesleff ${ }^{1}$, DR Roop ${ }^{3}$ and MI Koster ${ }^{\star 3}$}

1 Developmental Biology Program, Institute of Biotechnology, University of Helsinki, Helsinki, Finland;
2 Department of Dermatology, University of Rome 'Tor Vergata', Rome, Italy and

${ }^{3}$ Department of Dermatology, Charles C Gates Regenerative Medicine and Stem Cell Biology Program, University of Colorado Denver, Aurora, CO, USA

* Corresponding author: MI Koster, Department of Dermatology, Charles C Gates Regenerative Medicine and Stem Cell Biology Program, University of Colorado Denver, PO Box 6511, Mail Stop 8320, Aurora, CO 80045, USA.

Tel: + 303724 1640; Fax: + 303724 3051;

E-mail: Maranke.Koster@ucdenver.edu 
1. Yang A et al. Mol Cell 1998; 2: 305-316.

2. Koster MI, Roop DR. J Invest Dermatol 2008; 128: 1617-1619.

3. Yang A et al. Nature 1999; 398: 714-718.

4. Mills AA, Qi Y, Bradley A. Genesis 2002; 32: 138-141.

5. Keyes WM, Wu Y, Vogel H, Guo X, Lowe SW, Mills AA. Genes Dev 2005; 19: 1986-1999

6. Mills AA, Zheng B, Wang XJ, Vogel H, Roop DR, Bradley A. Nature 1999; 398: 708-713.

7. Laurikkala J, Mikkola ML, James M, Tummers M, Mills AA, Thesleff I. Development 2006; 133: $1553-1563$.

8. Kurita T, Cunha GR, Robboy SJ, Mills AA, Medina RT. Mech Dev 2005; 122: 1043-1055.

9. Ihrie RA et al. Cell 2005; 120: 843-856.

10. Koster MI, Kim S, Mills AA, DeMayo FJ, Roop DR. Genes Dev 2004; 18: 126-131.
11. Lo lacono $\mathrm{N}$ et al. Development 2008; $135: 1377-1388$

12. Kurita T, Mills AA, Cunha GR. Development 2004; 131: 1639-1649.

13. Kurita T, Medina RT, Mills AA, Cunha GR. Development 2004; 131: 4955-4964.

14. Daniely Y et al. Am J Physiol Cell Physiol 2004; 287: C171-C181.

15. Cheng W et al. Development 2006; 133: 4783-4792.

16. Lechler T, Fuchs E. Nature 2005; 437: 275-280.

17. Petre-Lazar B et al. J Cell Physiol 2007; 210: 87-98.

18. Wolff S, Talos F, Palacios G, Beyer U, Dobbelstein M, Moll UM. Cell Death Differ 2009; 16 : $1108-1117$.

19. Zheng B, Mills AA, Bradley A. Nucl Acids Res 1999; 27: 2354-2360.

20. Aberdam D, Mantovani R. Cell Death Differ 2009; 16: 1073-1074. 